\title{
Estimating neutral nanoparticle steady-state size distribution and growth according to measurements of intermediate air ions
}

\author{
H. Tammet, K. Komsaare, and U. Hõrrak \\ Institute of Physics, University of Tartu, 18 Ülikooli St., 50090, Tartu, Estonia \\ Correspondence to: H. Tammet (hannes.tammet@ut.ee) \\ Received: 25 February 2013 - Published in Atmos. Chem. Phys. Discuss.: 23 May 2013 \\ Revised: 21 August 2013 - Accepted: 22 August 2013 - Published: 27 September 2013
}

\begin{abstract}
Continuous measurements of intermediate air ion size distributions were carried out in the small town Tartu, Estonia, from 1 April 2010 through 7 November 2011. The intermediate ions are charged aerosol particles of diameter $1.5-7.5 \mathrm{~nm}$. In this paper we study what information about neutral nanoparticles of atmospheric aerosols can be drawn from the air ion measurements. Rough estimates of the growth rate and the size distribution of neutral nanoparticles were derived for the subset of measurements while the concentration of the intermediate ions was close to the median and remains in the range of $21 \pm 2 \mathrm{~cm}^{-3}$. This criterion excludes the specific new particle formation events characterized with high concentration of intermediate ions and includes only most typical quiet periods between the events when the simultaneous growth, depletion and recharging of particles are described with steady-state equations. We estimated the growth rate of nanoparticles to be about $2 \mathrm{~nm} \mathrm{~h}^{-1}$ while the growth flux or apparent nucleation rate proved to be about $0.5 \mathrm{~cm}^{-3} \mathrm{~s}^{-1}$ at $3 \mathrm{~nm}$ and about $0.08 \mathrm{~cm}^{-3} \mathrm{~s}^{-1}$ at $7 \mathrm{~nm}$. The results suggest that the process of new particle formation is not interrupted during the quiet periods between events of intensive nucleation of atmospheric aerosols.
\end{abstract}

\section{Introduction}

The fine nanometer component of atmospheric aerosol is crucial for understanding the formation of new secondary aerosol particles (Kulmala et al., 2013). Intermediate air ions are the finest electrically charged aerosol particles with an electric mobility of about $0.03-0.5 \mathrm{~cm}^{2} \mathrm{~V}^{-1} \mathrm{~s}^{-1}$ and a diameter of about 1.5-7.5 nm (Hõrrak et al., 2000; Hirsikko et al., 2011; Tammet et al., 2012). Every new particle should grow through this size range, where little is known about the factors and parameters of aerosol evolution when compared with the range of larger particles (Kulmala et al., 2004a, b, 2007, 2012, 2013).

High concentrations of intermediate ions appear in atmospheric air during burst events of new particle formation, which typically last a few hours (Kulmala et al., 2012). The quiet periods between the events are characterized by a low concentration of intermediate ions and can last for weeks (Tammet et al., 2012). During these periods the old burstgenerated nanoparticles grow to larger sizes, coagulated with large particles or deposited. However, intermediate ions are still found in the air during the long pauses between the events of burst-wise formation of new nanoparticles, which proves that atmospheric aerosol nucleation is continuous (Tammet et al., 2012). Knowledge about the role of quiet periods in the formation of atmospheric aerosol is limited. One reason for this is the technical difficulty due to the very low concentration of nanoparticles. The median concentration of intermediate ions of one polarity is about $20 \mathrm{~cm}^{-3}$, while Kulmala et al. (2004b) wrote that the sensitivity of electrometers was limited with the lowest detectable particle concentration of about $50 \mathrm{~cm}^{-3}$ when the cited paper was written. The sensitivity of ion spectrometers has been significantly improved during recent years, and new instruments (Mirme et al., 2007; Tammet, 2011) make the measurement of intermediate ion concentrations of less than $10 \mathrm{~cm}^{-3}$ possible. Tammet et al. (2012) have obtained a dataset of intermediate ion mobility and size distribution measurements that cover the periods of quiet nucleation with low-noise measurements.

Both electrically charged and neutral nanoparticles participate in the process of new particle formation in the 
Table 1. Near-median size distribution of intermediate ions in Tartu, Estonia, according to Tammet et al. (2012). The upper index indicates the polarity of ions while $n_{1}(d)$ without the upper index denotes the mean of positive and negative ions.

\begin{tabular}{lllllllllll}
\hline$d, \mathrm{~nm}$ & 1.62 & 1.87 & 2.18 & 2.56 & 3.04 & 3.60 & 4.25 & 5.01 & 5.88 & 6.89 \\
\hline$n_{1}^{+}(d), \mathrm{cm}^{-3} \mathrm{~nm}^{-1}$ & 10.96 & 5.60 & 4.04 & 3.33 & 3.01 & 2.85 & 2.91 & 2.89 & 2.87 & 3.20 \\
$n_{1}^{-}(d), \mathrm{cm}^{-3} \mathrm{~nm}^{-1}$ & 12.72 & 5.86 & 4.20 & 3.39 & 2.95 & 2.88 & 2.88 & 2.86 & 2.82 & 2.95 \\
$n_{1}(d), \mathrm{cm}^{-3} \mathrm{~nm}^{-1}$ & 11.84 & 5.73 & 4.12 & 3.36 & 2.98 & 2.87 & 2.89 & 2.88 & 2.85 & 3.07 \\
\hline
\end{tabular}

atmosphere while intermediate ions usually make up only a small percent of all nanoparticles. The aim of the present study is to learn what information about neutral nanoparticles can be drawn from intermediate ion measurements during quiet periods of new particle formation. In contrast to an earlier study by Hõrrak et al. (1998), the effect of particle growth and coagulation sink will be considered as factors of particle charge balance.

Characteristic durations of intermediate ion transition processes are typically less than one hour while the observed size distribution during quiet periods of new particle formation remains stable for many hours. Thus, a steady state can be expected in the theoretical model of aerosol dynamics, which significantly simplifies the discussion.

\section{Theoretical model}

The model is similar to that used by Iida et al. (2008) and based on the following assumptions:

1. nanoparticles are neutral or singly charged spheres;

2. their concentrations are low enough to neglect the nanoparticle-nanoparticle coagulation;

3. the product of ion-particle attachment coefficient and concentration of small ions does not depend on the polarity of electric charge (weak polarity symmetry);

4. all processes are in a steady state.

Iida et al. (2008) accepted the common assumption of strong polarity symmetry assuming the concentrations of positive and negative small ions to be equal: $c^{+}=c^{-}$. This proposal was discussed and recognized as restrictive in several papers (e.g., by Gagné et al., 2012). The assumption of weak symmetry tolerates the inequality of concentrations while the products of concentrations and attachment coefficients remain symmetric. The assumption is motivated by the fact that the concentrations of small ions appear in equations only in combination with corresponding attachment coefficients, and the small ion generation and recombination are inherently polarity symmetric. The steady-state balance of small ions is described by the following equation:

$$
\left.\begin{array}{l}
I^{+}=\alpha c^{-} c^{+}+\overline{\beta_{0}^{+}} c^{+} N_{\text {total }} \\
I^{-}=\alpha c^{+} c^{-}+\overline{\beta_{0}^{-}} c^{-} N_{\text {total }}
\end{array}\right\},
$$

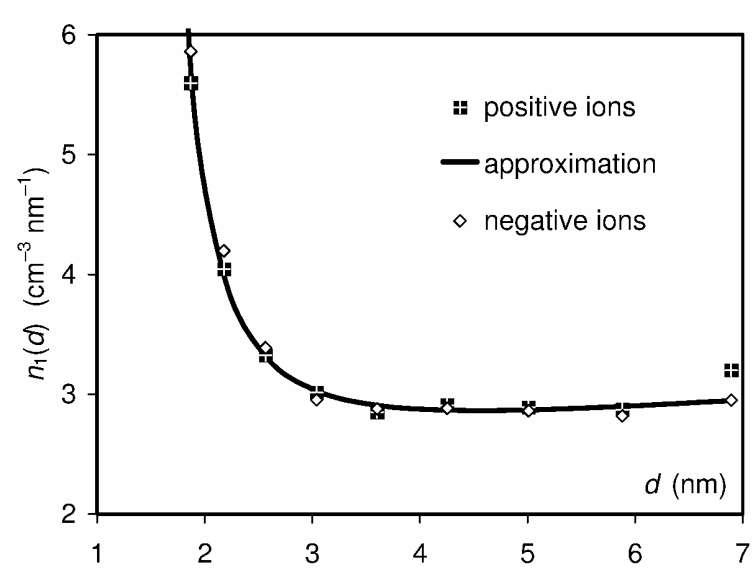

Fig. 1. Near-median size distribution of intermediate ions $n_{1}(d)$ according to Table 1 and the approximation Eq. (4).

where $I^{+}$and $I^{-}$are the rates of ion generation, $\alpha$ is the ionion recombination coefficient, $N_{\text {total }}$ is the total concentration of background aerosol particles, and $\beta$ 's are the effective integral attachment coefficients (Salm and Tamm, 2011) for indicated polarity. Ionization and recombination of small ions are symmetric: $I^{+}=I^{-}$and $\alpha c^{+} c^{-}=\alpha c^{-} c^{+}$. It follows exact symmetry $\overline{\beta_{0}^{+}} c^{+}=\overline{\beta_{0}^{-}} c^{-}$for integral attachment terms. We anticipate that the error caused by a possible violation of the weak symmetry in case of particles with specific sizes is small and can be neglected. This conclusion is supported by measurements (Tammet et al., 2012) that show only very small deviations from the polarity symmetry of intermediate ion concentrations in conditions of steady state (see Table 1 and Fig. 1).

The presumption of steady state is motivated by the fact that the characteristic recombination time of intermediate ions is typically less than one hour while the periods of quiet formation of new particles last many hours and days. Additionally, this presumption allows one to assume that the large preexisting background aerosol particles are in equilibrium charging state.

Dynamics of intermediate ions in the case of similar assumptions is described by Iida et al. (2008, Eq. 6). In the steady state, the derivatives according to time are zero. In this case the intermediate ion balance is described with a system of two differential equations: 


$$
\begin{aligned}
& \frac{d\left(\mathrm{GR}_{0}(d) n_{0}(d)\right)}{d d}=2 c \beta_{1}(d) n_{1}(d) \\
& -2 c \beta_{0}(d) n_{0}(d)-S_{b k g 0}(d) n_{0}(d), \\
& \frac{d\left(\mathrm{GR}_{1}(d) n_{1}(d)\right)}{d d}=c \beta_{0}(d) n_{0}(d)-c \beta_{1}(d) n_{1}(d) \\
& -S_{b k g 1}(d) n_{1}(d),
\end{aligned}
$$

where $n_{0}(d)=d N_{0} / d d$ is the distribution of neutral nanoparticle number concentration, $n_{1}(d)=d N_{1} / d d$ is the distribution of charged nanoparticle (intermediate ion) number concentration for one polarity, $\mathrm{GR}_{0}(d)$ and $\mathrm{GR}_{1}(d)$ are the growth rates of neutral and charged nanoparticles of diameter $d, c$ is the concentration of small ions of one polarity, $\beta_{0}(d)$ is the small ion to neutral particle attachment coefficient, and $\beta_{1}(d)$ is the small ion attachment coefficient to oppositely charged particle. The products $\mathrm{GR}_{0}(d) n_{0}(d)$ and $\mathrm{GR}_{1}(d) n_{1}(d)$ are called the growth fluxes or apparent nucleation rates (Kerminen and Kulmala, 2002). The attachment coefficients can be estimated according to the theory by Hoppel and Frick (1986, 1990) or approximations of tables by Hoppel and Frick; we use the approximation by Tammet and Kulmala (2005). $S_{b k g 0}(d)$ and $S_{b k g 1}(d)$ are the sinks of neutral and charged nanoparticles due to other factors. We call these quantities the coagulation sinks assuming they are caused predominantly by the coagulation of nanoparticles with coarse particles of the pre-existing background aerosol. All polaritydependent quantities are presented with averages for positive and negative particles. Equations (2) and (3) contain 8 functions of the particle diameter $\mathrm{GR}_{0}(d), \mathrm{GR}_{1}(d), n_{0}(d), n_{1}(d)$, $\beta_{0}(d), \beta_{1}(d), S_{b k g 0}(d), S_{b k g 1}(d)$, and one parameter $c$ that is independent of the diameter. Some of these quantities are easy to measure or calculate; some are not. In following the concentration of small ions $c$ and intermediate ion size distribution $n_{1}(d)$ on some finite set of diameters are expected to be known as measurements while the growth rates and distribution of neutral nanoparticles $n_{0}(d)$ are subjects to be estimated.

\section{Size distribution of charged nanoparticles}

Sample data are required for illustrating the methods of solving specific problems. We use results of long-term measurements of small and intermediate ions in the city of Tartu, Estonia (Tammet et al., 2012). Tartu is a small town with about 100000 inhabitants and without heavy industry. The instruments were installed on the top of a four-story building close to the town center $\left(58.373^{\circ} \mathrm{N}, 26.727^{\circ} \mathrm{E} ; 70 \mathrm{~m}\right.$ a.s.1.). The measurements were carried out from 1 April 2010 to 7 November 2011. The median of intermediate ion concentration of one polarity was $21 \mathrm{~cm}^{-3}$; 905 hourly records with the concentration of $21 \pm 2 \mathrm{~cm}^{-3}$ were gathered into a nearmedian sample. The burst events of new particle formation are reliably excluded because the upper border of $23 \mathrm{~cm}^{-3}$ is substantially below the level characterizing the burst events. The mean size distribution of intermediate ions in the sample is presented in Table 1.

Some other parameters of the same near-median sample were the mean values of air temperature of $7^{\circ} \mathrm{C}$, pressure of $1007 \mathrm{mb}$, and the concentration of small ions of one polarity $c=450 \mathrm{~cm}^{-3}$.

A theoretical model requires knowledge of $n_{1}(d)$ as a continuous function while the measurements are able to immediately provide only a discrete set of values, as presented in Table 1 . A continuous function $n_{1}(d)$ can be created as a mathematical interpolation based on a parameterization of the size distribution. We use the following parameterization:

$n_{1}(d) \approx\left(p_{1}+d / p_{2}+\frac{p_{3}}{\left(d-p_{4}\right)^{2}}\right) \mathrm{cm}^{-3} \mathrm{~nm}^{-1}$.

The values of the intermediate ion size distribution $n_{1}(d)$ presented in Table 1 are well approximated with the model in Eq. (4) at $p_{1}=2.45, p_{2}=15 \mathrm{~nm}, p_{3}=1.2 \mathrm{~nm}^{2}$, and $p_{4}=1.25 \mathrm{~nm}$. Measurements and the continuous approximation in Eq. (4) are compared in Fig. 1. Fluctuations of the marked points near the interpolated curve in Fig. 1 illustrate the level of random noise in measurements.

\section{Coagulation sink of nanoparticles and small ions}

Lehtinen et al. (2007) showed that the sink of neutral nanoparticles of diameter $d$ on the particles of a background aerosol is approximately proportional to $d^{-1.6}$. Tammet and Kulmala (2012) studied the sink of nanoparticles and small ions using a large set of aerosol size distribution measurements in Hyytiälä, Finland, and found that about $90 \%$ of the sink was caused by the background aerosol particles of the diameter between 50 and $500 \mathrm{~nm}$, whose number concentration is denoted by $N_{50-500}$. Results of the European aerosol measurement network (Asmi et al., 2011) show the typical values of $N_{50-500}$ in the hemiboreal zone as 1000 $3000 \mathrm{~cm}^{-3}$. According to earlier measurements by Kikas et al. (1996), the typical values in Tartu are in the same concentration range. Tammet and Kulmala (2012) correlated the sink of nanoparticles and ions with $N_{50-500}$ and found empiric regressions:

$$
\begin{aligned}
& S_{b k g 0}(d) \approx \frac{1.45 N_{50-500}}{(d / 1 \mathrm{~nm})^{1.6}} 10^{-6} \mathrm{~cm}^{3} \mathrm{~s}^{-1}, \\
& S_{b k g 1}(d) \approx\left(1+\frac{1.5}{\sqrt{d / 1 \mathrm{~nm}}}-\frac{4}{(d / 1 \mathrm{~nm}+2)^{2}}\right) S_{b k g 0}(d), \\
& S_{b k g 1.5 \text { ion }} \approx\left(3.9 \times 10^{-6} \mathrm{~cm}^{3} \mathrm{~s}^{-1}\right) N_{50-500} .
\end{aligned}
$$

Here $S_{b k g 1.5 \text { ion }}$ is the sink of typical small ions with the electric mobility of $1.5 \mathrm{~cm}^{2} \mathrm{~V}^{-1} \mathrm{~s}^{-1}$. The sink of charged nanoparticles exceeds the sink of neutral particles because the attachment of ions to oppositely charged particles is 
strongly enhanced and not fully compensated by the reduction of the attachment in the case of coinciding polarities. The dispersion between actual values of the sink and the regressions (Eqs. 5-7) appeared to be pretty large: the relative standard deviation is about $30 \%$ in the dataset of measurements in Hyytiälä for three years. In the present study, high accuracy is not required because the regressions are necessary only for the association of illustrating calculations with the trial values of the background aerosol concentrations.

\section{Distribution of neutral nanoparticles at uniform growth of the intermediate ions}

The formal problem includes the size distribution of charged nanoparticles as the input, and growth rates and size distribution of neutral nanoparticles as the unknowns to be estimated. Unfortunately, the system of two equations (Eqs. 2 and 3) itself cannot offer an unambiguous solution of the problem without involving some additional information. The additional information may contain supplementary measurements or prior knowledge as well as reasonable hypotheses about the unknown quantities. There are numerous possibilities to include additional information. In the following we discuss a particular approach whereby the growth of intermediate ions is postulated to be uniform and $d \mathrm{GR}_{1} / d d=0$, as often assumed in studies of atmospheric aerosol nucleation (Gagné et al., 2012). Recent results by Kulmala et al. (2013) confirmed the hypothesis of nearly uniform growth for nanoparticles with diameters greater than $2.5 \mathrm{~nm}$ but showed it to be inadequate for particles with diameters less than $2 \mathrm{~nm}$. The size range of nanoparticles in the quantitative examples below will be limited with diameters of $2-7 \mathrm{~nm}$, and the results for the lowest half nanometer may contain distortions due to the deviation from the hypothesis of uniform growth.

If the coagulation sink of charged nanoparticles $S_{b k g 1}(d)$ is known, the distribution of intermediate ions $n_{1}(d)$ is ascertained by measurement, and $\mathrm{GR}_{1}$ is a known constant, then the distribution of neutral nanoparticles $n_{0}(d)$ is unambiguously determined according to Eq. (3) and can be expressed as

$n_{0}(d)=\frac{c \beta_{1}(d)+S_{b k g 1}(d)}{c \beta_{0}(d)} n_{1}(d)+\frac{\mathrm{GR}_{1}}{c \beta_{0}(d)} \frac{d n_{1}(d)}{d d}$.

Equation (8) requires knowledge of $n_{1}(d)$ as a continuous function, e.g., as represented with the interpolation model (Eq. 4). The coagulation sink of charged nanoparticles $S_{b k g 1}(d)$ can be roughly estimated according to Eqs. (5) and (6). Unfortunately, we have no simultaneous measurements of $N_{50-500}$ available in the present study and can perform only illustrative calculations based on hypothetic values assumed to be close to the typical values. Examples in Figs. 2 and 3 are drawn assuming $N_{50-500}=2000 \mathrm{~cm}^{-3}$ in accordance with the measurements by Kikas et al. (1996).

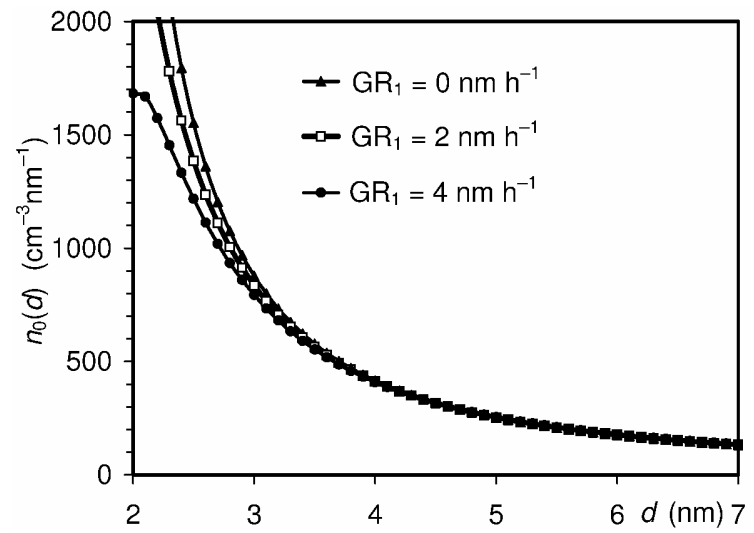

Fig. 2. Size distributions of neutral nanoparticles $n_{0}(d)$ in case of the near-median distribution of intermediate ions in Tartu (Fig. 1) and $N_{50-500}=2000 \mathrm{~cm}^{-3}$ calculated according to Eq. (8) for the trial values of charged nanoparticle growth rate $\mathrm{GR}_{1}$.

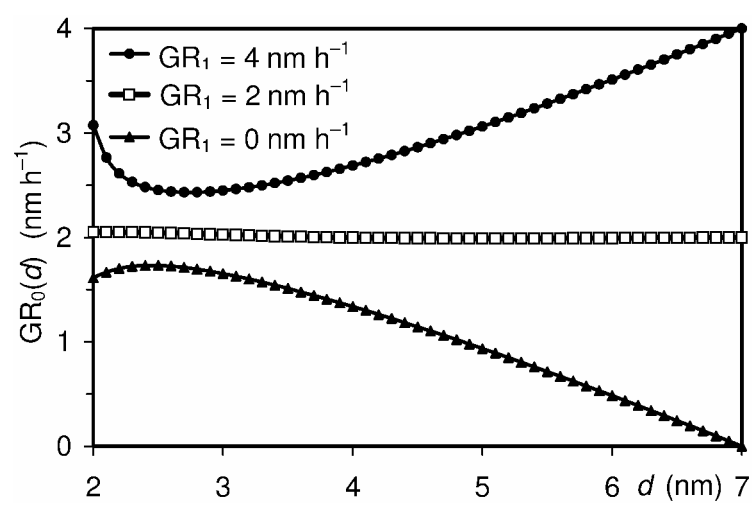

Fig. 3. Growth rate of neutral nanoparticles $\mathrm{GR}_{0}(d)$ in case of the near-median distribution of intermediate ions in Tartu (Fig. 1) and $N_{50-500}=2000 \mathrm{~cm}^{-3}$ calculated according to Eq. (9) at the assumption $\mathrm{GR}_{0}(7 \mathrm{~nm})=\mathrm{GR}_{1}$ for the trial values of charged nanoparticle growth rate $\mathrm{GR}_{1}$.

The effect of different assumptions about $N_{50-500}$ will be illustrated afterward in Fig. 4.

Figure 1 shows that the size distribution curve $n_{1}(d)$ is flat in the size range of 3-6 $\mathrm{nm}$, where values of the derivative are small and the last term in Eq. (8) turns out to be insignificant. Thus the estimate of $n_{0}(d)$ in this size range is nearly independent of the growth rate $\mathrm{GR}_{1}$. This fact is illustrated in Fig. 2 with the curves of $n_{0}(d)$ calculated according to Eq. (8) for different hypothetic values of $\mathrm{GR}_{1}$ while considering all terms in Eq. (8). The curve at $\mathrm{GR}_{1}=2 \mathrm{~nm} \mathrm{~h}^{-1}$ differs only a little from the curve at $\mathrm{GR}_{1}=0 \mathrm{~nm} \mathrm{~h}^{-1}$, which presents an unreal hypothetic situation when particles grow only in neutral state. The conclusion is that the assumption about the growth rate of charged particles in the present model has only a minor effect on the estimates of the concentration and size distribution of neutral nanoparticles during quiet periods of new particle formation. 


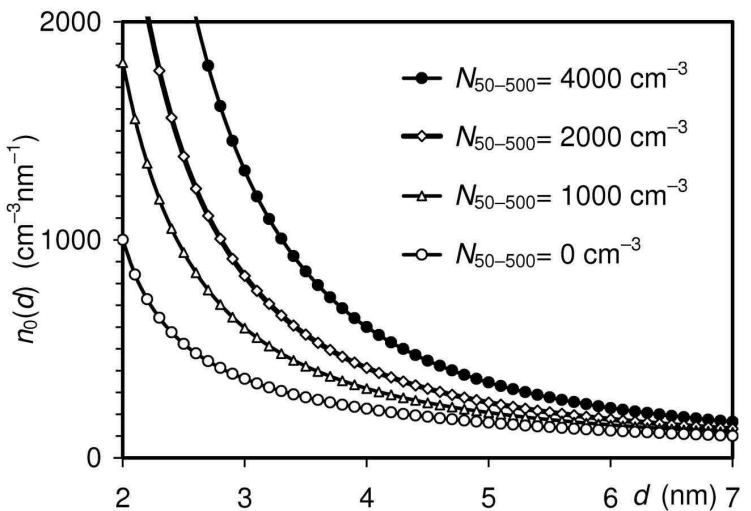

Fig. 4. Size distributions of neutral nanoparticles $n_{0}(d)$ in case of the near-median distribution of intermediate ions in Tartu (Fig. 1) calculated according to Eqs. (8) and (9) at constraints $\mathrm{GR}_{0}(3 \mathrm{~nm})=\mathrm{GR}_{0}(7 \mathrm{~nm})=\mathrm{GR}_{1}$ and different trial values of the concentration of background aerosol particles $N_{50-500}$. The growth rate was estimated to be $0 \mathrm{nmh}^{-1}$ at $N_{50-500}=0 \mathrm{~cm}^{-3}, \quad 1.15 \mathrm{~nm} \mathrm{~h}^{-1}$ at $N_{50-500}=1000 \mathrm{~cm}^{-3}$, $2.03 \mathrm{~nm} \mathrm{~h}^{-1}$ at $N_{50-500}=2000 \mathrm{~cm}^{-3}$, and $3.6 \mathrm{~nm} \mathrm{~h}^{-1}$ at $N_{50-500}=4000 \mathrm{~cm}^{-3}$.

\section{Estimating the growth rate and the growth flux of nanoparticles}

Let us choose a hypothetic value of $\mathrm{GR}_{1}$ and determine $n_{0}(d)$ according to Eq. (8). In this case Eq. (2) contains one unknown function $\mathrm{GR}_{0}(d)$ and can be transfigured into the traditional general form of a linear differential equation:

$$
\begin{aligned}
& \frac{d \mathrm{GR}_{0}(d)}{d d}+\frac{1}{n_{0}(d)} \frac{d n_{0}(d)}{d d} \mathrm{GR}_{0}(d)=2 c \beta_{1}(d) \frac{n_{1}(d)}{n_{0}(d)} \\
& -2 c \beta_{0}(d)-S_{b k g 0}(d) .
\end{aligned}
$$

Equation (9) can easily be integrated when an initial value $\mathrm{GR}_{0}\left(d_{0}\right)$ at an arbitrary diameter $d_{0}$ is known. It is assumed that a possible dependence of the growth rate on the particle charge fades with an increase in particle size. Thus the hypothesis $\mathrm{GR}_{0}(7 \mathrm{~nm})=\mathrm{GR}_{1}$ seems to be an acceptable initial condition. Corresponding solutions of Eq. (9) are shown in Fig. 3, which is complementary to Fig. 2.

Two curves of the three depicted in Fig. 3 distinctly contradict the common assumption about the nearly constant growth rate of neutral particles. The prior information contained in assumptions $\mathrm{GR}_{0}(7 \mathrm{~nm})=\mathrm{GR}_{1}$ and $\mathrm{GR}_{0}(d) \approx$ const allows us to pick out $\mathrm{GR}_{1} \approx 2 \mathrm{~nm} \mathrm{~h}^{-1}$ as the most realistic choice among the three trial values tested in Fig. 3. This example brings out a rule for choosing the value of $\mathrm{GR}_{1}$ according to the principle of the minimum variation of $\mathrm{GR}_{0}(d)$ calculated according to Eq. (9). A simple approximate method assumes the exact coincidence of $\mathrm{GR}_{0}$ and $\mathrm{GR}_{1}$ at two different diameters. In this case the set of free parameters is reduced to one parameter $N_{50-500}$, and the choice of this parameter unambiguously determines the growth rate. Figure 4

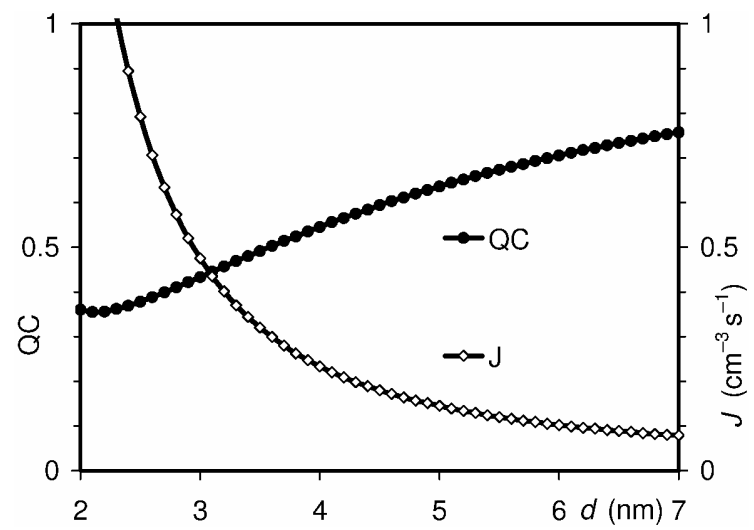

Fig. 5. Charging coefficient QC and the growth flux or apparent nucleation rate $J$ (Eq. 12) estimated according to the present model and the near-median distribution of intermediate air ions in Tartu (Fig. 1) assuming $\mathrm{GR}_{0}(3 \mathrm{~nm})=\mathrm{GR}_{0}(7 \mathrm{~nm})=\mathrm{GR}_{1}$ and $N_{50-500}=2000 \mathrm{~cm}^{-3}$.

shows a sample of solution demonstrating the effect of different hypotheses about the concentration of the background aerosol particles on the estimate of neutral nanoparticle distribution at constraints $\mathrm{GR}_{0}(3 \mathrm{~nm})=\mathrm{GR}_{0}(7 \mathrm{~nm})=\mathrm{GR}_{1}$.

One way to acquire more additional information is to measure the ionization rate $I$ simultaneously with air ions. The balance of small ions in steady state is described with the following equation:

$I=\alpha c^{2}+S_{b k g 1.5 \text { ion }} c$,

where $\alpha \approx 1.6 \times 10^{-6} \mathrm{~cm}^{3} \mathrm{~s}^{-1}$ is the ion-ion recombination coefficient and $S_{b k g 1.5}$ ion is the aerosol sink of small ions of the typical mobility of $1.5 \mathrm{~cm}^{2} \mathrm{~V}^{-1} \mathrm{~s}^{-1}$ related to the aerosol concentration according to empiric regression in Eq. (7). If the ionization rate is known, then Eq. (10) enables one to estimate the sink of small ions according to the measured concentration and apply Eq. (7) to estimate the value of background aerosol particle concentration $N_{50-500}$. Simultaneous measurement of the intermediate ion size distribution, concentration of small ions and ionization rate would enable one to get adjusted results about the growth rate and distribution of neutral nanoparticles. Examples at $c=450 \mathrm{~cm}^{-3}$ and a set of trial values of $I$ presented in Table 2 are in good accordance with assumptions $\mathrm{GR}_{1} \approx 2 \mathrm{~nm} \mathrm{~h}^{-1}$ and $N_{50-500} \approx 2000 \mathrm{~cm}^{-3}$ about the typical distribution of intermediate ions in Tartu, which is illustrated in Fig. 1.

Some additional results are presented in Fig. 5. Here the charging coefficient is introduced:

$\mathrm{QC}(d)=\frac{n_{1}(d) \beta_{1}(d)}{n_{0}(d) \beta_{0}(d)}$,

which characterizes how much the charging state deviates from the hypothetic value corresponding to the zero sink of non-growing nanoparticles on the background aerosol. The 
Table 2. Estimates of the background aerosol particle number concentration $N_{50-500}$ and the growth rate of nanoparticles according to Eqs. (7)-(10) at constraints $\mathrm{GR}_{0}(3 \mathrm{~nm})=\mathrm{GR}_{0}(7 \mathrm{~nm})=\mathrm{GR}_{1}$ and $c=450 \mathrm{~cm}^{-3}$ depending on the trial value of ionization rate. STD is the standard deviation of difference $\left(\mathrm{GR}_{0} / \mathrm{GR}_{1}-1\right)$ in the range of diameters of $2-7 \mathrm{~nm}$.

\begin{tabular}{lllll}
\hline Ionization rate $\mathrm{cm}^{-3} \mathrm{~s}^{-1}$ & 2 & 4 & 6 & 8 \\
\hline$N_{50-500}, \mathrm{~cm}^{-3}$ & 960 & 2100 & 3250 & 4370 \\
$\mathrm{GR}_{1}, \mathrm{~nm} \mathrm{~h}^{-1}$ & 1.1 & 2.1 & 3.0 & 3.9 \\
$\mathrm{STD}$ & $0.8 \%$ & $1.0 \%$ & $1.8 \%$ & $2.6 \%$ \\
\hline
\end{tabular}

value of QC approaches 1 with a simultaneous decrease in $N_{50-500}$ and $\mathrm{GR}_{1}$. The growth flux

$J(d)=\mathrm{GR}_{0}(d) n_{0}(d)+2 \mathrm{GR}_{1}(d) n_{1}(d)$

is the same as the apparent nucleation rate explained by Kerminen and Kulmala (2002) and Lehtinen et al. (2007). The standard $3 \mathrm{~nm}$ apparent nucleation rate at the nearmedian distribution of intermediate air ions in Tartu and $N_{50-500}=2000 \mathrm{~cm}^{-3}$ appears to be about $0.5 \mathrm{~cm}^{-3} \mathrm{~s}^{-1}$, which means a considerable formation of new nanoparticles during quiet periods of new particle formation. Most of these nanoparticles are still scavenged by the large particles of the background aerosol, and the flux passing the border of $7 \mathrm{~nm}$ is decreased about 6 times until the value of about $0.08 \mathrm{~cm}^{-3} \mathrm{~s}^{-1}$.

\section{Conclusions}

The assumption of equal concentrations of positive and negative small ions can be replaced with the assumption of weak polarity symmetry, which states that the product of ionparticle attachment coefficient and concentration of small ions is independent on the polarity and tolerates the inequality of polar concentrations of small ions. This assumption is supported by the polarity symmetry of intermediate ion concentration measurements during quiet periods of new particle formation.

Contemporary instruments allow the measurement of size distributions of intermediate ions when the values of $d N_{1} / d d$ are as low as a few $\mathrm{cm}^{-3} \mathrm{~nm}^{-1}$. If the coagulation sink, the growth rate, and the size distribution of intermediate ions are known, then the equation of steady state (Eq. 3) provides explicit expression (Eq. 8) for the size distribution of neutral nanoparticles. Variation in the growth rate of intermediate ions has only a minor effect on the estimate of size distribution of neutral nanoparticles during quiet periods of new particle formation. Plausible values of the growth rates can be found when minimizing the difference between the trial growth rate of charged nanoparticles and the growth rates of neutral nanoparticles calculated according to the steady-state equations (Eqs. 2 and 9).
Correct evaluation of the size distribution and growth rate of neutral nanoparticles according to air ion measurements requires simultaneous measurement of the background aerosol particle concentration or the ionization rate. The discussed measurements were not accompanied by simultaneous measurements of these quantities. Thus only rough estimates were derived using the typical concentrations of background aerosol measured in the same location during earlier studies. The growth rate of nanoparticles in urban air of a small town in the case of near-median concentration of intermediate ions was estimated to be about $2 \mathrm{~nm} \mathrm{~h}^{-1}$ and the growth flux or apparent nucleation rate about $0.5 \mathrm{~cm}^{-3} \mathrm{~s}^{-1}$ at $3 \mathrm{~nm}$ and $0.08 \mathrm{~cm}^{-3} \mathrm{~s}^{-1}$ at $7 \mathrm{~nm}$. The results suggest that the process of new particle formation is not interrupted during the quiet periods between the events of intensive nucleation of atmospheric aerosols.

Acknowledgements. This research was supported by the Estonian Science Foundation through grant 8342, the Estonian Research Council Targeted Financing Project SF0180043s08 and the European Regional Development Fund through the Environmental Conservation and Environmental Technology R\&D Programme project BioAtmos (3.2.0802.11-0043).

Edited by: A. Petzold

\section{References}

Asmi, A., Wiedensohler, A., Laj, P., Fjaeraa, A.-M., Sellegri, K., Birmili, W., Weingartner, E., Baltensperger, U., Zdimal, V., Zikova, N., Putaud, J.-P., Marinoni, A., Tunved, P., Hansson, H.C., Fiebig, M., Kivekäs, N., Lihavainen, H., Asmi, E., Ulevicius, V., Aalto, P. P., Swietlicki, E., Kristensson, A., Mihalopoulos, N., Kalivitis, N., Kalapov, I., Kiss, G., de Leeuw, G., Henzing, B., Harrison, R. M., Beddows, D., O’Dowd, C., Jennings, S. G., Flentje, H., Weinhold, K., Meinhardt, F., Ries, L., and Kulmala, M.: Number size distributions and seasonality of submicron particles in Europe 2008-2009, Atmos. Chem. Phys., 11, 5505-5538, doi:10.5194/acp-11-5505-2011, 2011.

Gagné, S., Leppä, J., Petäjä, T., McGrath, M. J., Vana, M, Kerminen,V.-M. , Laakso, L., and Kulmala, M.: Aerosol charging state at an urban site: new analytical approach and implications for ion-induced nucleation, Atmos. Chem. Phys., 12, 4647-4666, doi:10.5194/acp-12-4647-2012, 2012.

Hirsikko, A., Nieminen, T., Gagne, S., Lehtipalo, K., Manninen, H. E., Ehn, M., Hõrrak, U., Kerminen, V.-M., Laakso, L., McMurry, P. H., Mirme, A., Mirme, S., Petäjä, T., Tammet, H., Vakkari, V., Vana, M., and Kulmala, M.: Atmospheric ions and nucleation: a review of observations, Atmos. Chem. Phys., 11, 767798, doi:10.5194/acp-11-767-2011, 2011.

Hoppel,W. A. and Frick, G. M.: Ion-aerosol attachment coefficients and the steady-state charge distribution on aerosol in a bipolar environment, Aerosol Sci. Tech., 5, 1-21, 1986.

Hoppel, W. A. and Frick, G. M.: The nonequilibrium character of the aerosol charge distributions produced by neutralizes, Aerosol Sci. Tech., 12, 471-496, 1990. 
Hõrrak, U., Mirme, A., Salm, J., Tamm, E., and Tammet, H.: Air ion measurements as a source of information about atmospheric aerosols, Atmos. Res., 46, 233-242, 1998.

Hõrrak, U., Salm, J., and Tammet, H.: Statistical characterization of air ion mobility spectra at Tahkuse Observatory: classification of air ions, J. Geophys. Res.-Atmos., 105, 9291-9302, 2000.

Iida, K., Stolzenburg, M. R., McMurry, P. H., and Smith, J. N.: Estimating nanoparticle growth rates from sizedependent charged fractions: analysis of new particle formation events in Mexico City, J. Geophys. Res., 113, D05207, doi:10.1029/2007JD009260, 2008.

Kerminen, V.-M., and Kulmala, M.: Analytical formulae connecting the "real" and the "apparent" nucleation rate and the nuclei number concentration for atmospheric nucleation events, J. Aerosol Sci., 33, 609-622, 2002.

Kikas, Ü., Mirme, A., Tamm, E., and Raunemaa, T. : Statistical characteristics of aerosol in Baltic Sea region, J. Geophys. Res., 101D, 19319-19327, 1996.

Kulmala, M., Laakso, L., Lehtinen, K. E. J., Riipinen, I., Dal Maso, M., Anttila, T., Kerminen, V.-M., Hõrrak, U., Vana, M., and Tammet, H.: Initial steps of aerosol growth, Atmos. Chem. Phys., 4, 2553-2560, doi:10.5194/acp-4-2553-2004, 2004a.

Kulmala, M., Vehkamäki, H., Petäjä, T., Dal Maso, M., Lauri, A., Kerminen, V.-M., Birmili, W., and McMurry, P. H.: Formation and growth rates of ultrafine atmospheric particles: a review of observations, J. Aerosol Sci., 35, 143-176, 2004b.

Kulmala, M., Riipinen, I., Sipilä, M., Manninen, H. E., Petäjä, T., Junninen, H., Dal Maso, M., Mordas, G., Mirme, A., Vana, M., Hirsikko, A., Laakso, L., Harrison, R. M., Hanson, I., Leung, C., Lehtinen, K. E. J., and Kerminen, V.-M.: Toward direct measurement of atmospheric nucleation, Science, 318, 89-92, 2007.

Kulmala, M., Petäjä, T., Nieminen, T., Sipilä, M., Manninen, H. E., Lehtipalo, K., Dal Maso, M., Aalto, P. P., Junninen, H., Paasonen, P., Riipinen, I., Lehtinen, K. E. J., Laaksonen, A., and Kerminen, V.-M.: Measurement of the nucleation of atmospheric aerosol particles, Nat. Protoc., 7, 1651-1667, 2012.
Kulmala, M., Kontkanen, J., Junninen, H., Lehtipalo, K., Manninen, H. E., Nieminen, T., Petäjä, T., Sipilä, M., Schobesberger, S., Rantala, P., Franchin, A., Jokinen, T., Järvinen, E., Äijälä, M., Kangasluoma, J., Hakala, J., Aalto, P. P., Paasonen, P., Mikkilä, J., Vanhanen, J., Aalto, J., Hakola, H., Makkonen, U., Ruuskanen, T., Mauldin III, R. L., Duplissy, J., Vehkamäki, H., Bäck, J., Kortelainen, A., Riipinen, I., Kurtén, T., Johnston, M. V., Smith, J. N., Ehn, M., Mentel, T. F., Lehtinen, K. E. J., Laaksonen, A., Kerminen, V.-M., and Worsnop, D. R.: Direct observations of atmospheric aerosol nucleation, Science, 339, 943-946, 2013.

Lehtinen, K. E. J., Dal Maso, M., Kulmala, M., and Kerminen, V.M.: Estimating nucleation rates from apparent particle formation rates and vice versa: revised formulation of the KerminenKulmala equation, J. Aerosol Sci., 38, 988-994, 2007.

Mirme, A., Tamm, E., Mordas, G., Vana, M., Uin, J., Mirme, S., Bernotas, T., Laakso, L., Hirsikko, A., and Kulmala, M.: A widerange multi-channel Air Ion Spectrometer, Boreal Environ. Res., 12, 247-264, 2007.

Salm, J. and Tamm, E.: Dependence of the ion-aerosol equivalent attachment coefficient on the ratio of polar ponductivities in a pteady ptate, Aerosol Air Qual. Res., 11, 211-217, 2011.

Tammet, H.: Symmetric inclined grid mobility analyzer for the measurement of charged clusters and fine nanoparticles in atmospheric air, Aerosol Sci. Tech., 45, 468-479, 2011.

Tammet, H. and Kulmala, M.: Simulation tool for atmospheric aerosol nucleation bursts, J. Aerosol Sci., 36, 173-196, 2005.

Tammet, H. and Kulmala, M.: Empiric equations of coagulation sink of fine nanoparticles on background aerosol optimized for boreal zone, Boreal Environ. Res., accepted, 2012.

Tammet, H., Komsaare, K., and Hõrrak, U.: Intermediate ions in the atmosphere, Atmos. Res., in press, doi:10.1016/j.atmosres.2012.09.009, 2012. 